Check for updates

Cite this: RSC Adv., 2019, 9, 28019

\title{
Activation of atomically precise silver clusters on carbon supports for styrene oxidation reactions $\dagger$
}

\begin{abstract}
Kazeem O. Sulaiman, V. Sudheeshkumar and Robert W. J. Scott iD *
Metal clusters have distinct features such as large surface area, low-coordination-atom enriched surfaces, and discrete energy levels that influence their behavior during catalytic reactions. Atomically-precise $\mathrm{Ag}$ clusters, which are analogues of more well-studied Au clusters, are yet to be fully explored as catalysts for various chemical reactions. 2,4-Dimethylbenzenethiol-protected $\mathrm{Ag}_{25}$ clusters were prepared and deposited onto carbon supports followed by calcination. Results from X-ray absorption fine structure (EXAFS) spectroscopy measurements and other characterization techniques indicated that thermal activation of carbon-supported $\mathrm{Ag}_{25}$ clusters resulted in dethiolation of Ag clusters at $250{ }^{\circ} \mathrm{C}$ and beyond, and consequently mild growth in particle sizes of Ag clusters on carbon supports was seen with increasing activation temperatures. Both as-prepared and activated $\mathrm{Ag}_{25}$ clusters were active for styrene oxidation reactions, with high selectivity towards styrene oxide, without using any promoter. Results show that mild activation at $250{ }^{\circ} \mathrm{C}$ yields the most active catalysts, and higher activation temperatures lead to decreased activities and slightly poorer selectivity to styrene oxidation as a result of cluster sintering. EXAFS data shows the resulting activated clusters are composed of $\mathrm{Ag}$ metal and that all thiols are removed from the Ag cluster surfaces, though XPS data shows that thiol oxidation products are still present in the sample.
\end{abstract}

Received 18th July 2019

Accepted 29th August 2019

DOI: $10.1039 / \mathrm{c} 9 \mathrm{ra0} 5566 \mathrm{e}$

rsc.li/rsc-advances

\section{Introduction}

The use of well-defined clusters for the development of model heterogeneous catalysis is a very active research area. ${ }^{1,2}$ Noble metals with sizes in the nanoscale generally show excellent catalytic activity due to their enhanced surface-to-volume ratio which leads to more active sites, as well as having modified surface geometric and electronic properties compared to bulk materials. ${ }^{3,4}$ By tailoring the size as well as the morphology and composition, robust nanocatalysts with excellent catalytic activity and selectivity can be achieved. ${ }^{4}$ Atomically-precise thiolate ligand protected clusters are widely studied due to strong sulfur-metal interactions that enable good stability in solution, facile synthesis, and controlled cluster compositions as well as functionalization of stable clusters. ${ }^{5}$ Owing to possible influence of the capping ligand on the activity and/or selectivity of ligand-protected clusters in catalytic reactions, it is desirable to have partial or complete ligand removal to enhance contact between the surface metal atoms and reactants, and thus allow higher catalytic activity. ${ }^{5,6}$ This leads to a research challenge in preventing or controlling particle

Department of Chemistry, University of Saskatchewan, 110 Science Place, Saskatoon, Saskatchewan S7N 5C9, Canada. E-mail: robert.scott@usask.ca

$\uparrow$ Electronic supplementary information (ESI) available: XPS spectra for activated $\mathrm{Ag}_{25} /$ carbon catalyst sample, EXAFS fitting plots for as-prepared and activated samples, stability of dispersed $\mathrm{Ag}_{25} \mathrm{~L}_{18}{ }^{-}$clusters in solvents, and EXAFS fitting parameters for as-prepared sample. See DOI: 10.1039/c9ra05566e aggregation upon removal of ligands from the protected clusters at high loading on supports. Metal-support interactions can play a key role in stabilizing naked clusters, in addition to other strategies that involve creating physical barriers to minimize or prevent particle aggregation., ${ }^{7,8}$

Many research groups, including ours, have extensively studied $\mathrm{Au}_{25}(\mathrm{SR})_{18}{ }^{-}$clusters for various catalytic reactions. ${ }^{9-15} \mathrm{X}-$ ray absorption near edge structure (XANES) and extended X-ray absorption fine structure (EXAFS) techniques are components of X-ray absorption spectroscopy (XAS) which are often used in combination to probe chemical bonding and local structure properties of metal clusters with thiol ligands. ${ }^{12,16,17}$ Many research groups have demonstrated that XAS is a reliable bulk technique for following particle size growth upon thermal activation of supported $\mathrm{Au}$ clusters. ${ }^{12,18-20}$ Jin and coworkers showed that $\mathrm{Au}$-thiolate bonds are stable to heating until $125^{\circ} \mathrm{C}$ beyond which the metal clusters become deprotected. ${ }^{21} \mathrm{~A}$ number of research groups have observed sintering of $\mathrm{Au}$ clusters upon thermal activation at temperatures above $250{ }^{\circ} \mathrm{C}$ for supported clusters, though some supports show strong interaction with clusters which mitigate sintering. ${ }^{10,12,22-25}$ Other activation strategies include chemical approaches, which involve the use of oxidizing and reducing agents, as well as light-induced approaches. ${ }^{26-30}$ Both naked and protected $\mathrm{Au}_{25}$ clusters have been reported to be active catalysts for styrene oxidation, ${ }^{10,31}$ and several groups including our group have shown size-dependent activity of Au clusters, with high 
selectivity towards styrene oxide. ${ }^{\mathbf{1 0 , 1 3}} \mathrm{Ag}$ nanoparticles have also shown to be effective catalysts for styrene epoxidation, though the use of a secondary promoter is a common practice to achieve high selectivity of the epoxide product. ${ }^{32,33}$ Then, selective styrene epoxidation can serve as a good model oxidation reaction to assess the activity of atomically-precise $\mathrm{Ag}$ cluster catalysts.

A large number of ligand-protected $\mathrm{Ag}$ clusters such as $\mathrm{Ag}_{9}$, $\mathrm{Ag}_{10}, \mathrm{Ag}_{16}, \mathrm{Ag}_{25}, \mathrm{Ag}_{29}, \mathrm{Ag}_{32}$ and $\mathrm{Ag}_{44}$ have been reported in the literature. ${ }^{20,34-38} \quad \mathrm{Ag}_{25}(\mathrm{SR})_{18}{ }^{-}$clusters have similar (but not identical) atomic arrangements and ligand counts as $\mathrm{Au}_{25}(\mathrm{SR})_{18}{ }^{-}$clusters. Bakr and coworkers reported the successful synthesis and structural elucidation of $\mathrm{Ag}_{25}(\mathrm{SR})_{18}{ }^{-}$ clusters and noted that the crystal structure has four voids that can allow solvent coordination to give better stability of the clusters. ${ }^{5,39}$ The predisposition of silver (Ag) to oxidation, in spite of its lower cost and higher relative abundance (compared to $\mathrm{Au}$ ), imposes possible limitations on the development of heterogeneous catalysts based on thiolate-protected Ag clusters. Indeed, early work in the field suggested that Ag systems might behave significantly differently than analogous $\mathrm{Au}$ systems. Padmos and Zhang showed by XAS that as-synthesized small thiolate protected $\mathrm{Ag}$ nanoparticles look to have Ag cores and $\mathrm{Ag}_{2} \mathrm{~S}$ shells, while dialkylsulfide-stabilized $\mathrm{Ag}$ nanoparticles have pure $\mathrm{Ag}$ cores. $^{40}$ Pradeep and coworkers found that glutathione-stabilized $\mathrm{Ag}_{25} \mathrm{~L}_{18}$ clusters formed $\mathrm{Ag}_{2} \mathrm{~S}$ materials, as evidenced by PXRD, after heating at $80{ }^{\circ} \mathrm{C}$ in solution. ${ }^{36}$ However, later work by Tsukuda and coworkers employed XAS techniques to study the behavior of mesoporous carbon supported $\left[\mathrm{Ag}_{44}\left(\mathrm{SC}_{6} \mathrm{H}_{4} \mathrm{~F}\right)_{30}\right]^{-}$clusters upon thermal treatment. ${ }^{20}$ They observed sulfur-free $\mathrm{Ag}$ clusters upon calcination at $300{ }^{\circ} \mathrm{C}$, which were used as catalysts for the catalytic dehydrogenation of ammonia-borane. At the current time, it is not clear whether such discrepancies in results are due to ligand differences or due to improved purification protocols of $\mathrm{Ag}$ cluster materials. This manuscript employs XAS and other techniques to probe the behavior of 2,4-dimethylbenzenethiolate-protected $\mathrm{Ag}_{25}$ clusters upon thermal activation for heterogeneous catalysis.

In this study, the structural and morphological properties of the purified $\mathrm{Ag}_{25} \mathrm{~L}_{18}{ }^{-}$clusters, as catalyst precursors, were evaluated using characterization techniques such as UV-vis spectroscopy, thermal gravimetric analysis (TGA), and transmission electron microscopy (TEM), followed by monitoring the effect of choice of coordinating solvents and storage temperature on the stability of solvent dispersed $\mathrm{Ag}_{25} \mathrm{~L}_{18}{ }^{-}$clusters. Thereafter, $\mathrm{Ag}_{25} \mathrm{~L}_{18}{ }^{-}$clusters were supported on carbon supports and activated thermally, followed by characterization of carbon-supported $\mathrm{Ag}_{25}$ clusters using X-ray photoelectron spectroscopy (XPS), TEM, and XAS, and then examined for catalytic activity and selectivity for styrene oxidation reactions. Our results show that Ag-thiol bonds are selectively oxidized from the clusters upon mild heat treatments without formation of $\mathrm{Ag}_{2} \mathrm{O}$ or $\mathrm{Ag}_{2} \mathrm{~S}$, and that the activated $\mathrm{Ag}$ clusters on carbon supports showed particle size-dependent activity for styrene oxidation reactions.

\section{Experimental}

\section{Materials}

All chemicals are commercially available and used as received without any further purification. Silver nitrate $\left(\mathrm{AgNO}_{3}\right.$, $\geq 99.0 \%$ ), styrene (ReagentPlus ${ }^{\circledR}, 99.9 \%$ ), tert-butyl hydroperoxide $\left(t \mathrm{BuOOH}, \mathrm{TBHP}, 70 \%\right.$ in $\left.\mathrm{H}_{2} \mathrm{O}\right)$, high purity acetonitrile (MeCN) and 100\% ethanol (EtOH) were purchased from Sigma Aldrich. Dichloromethane $\left(\mathrm{CH}_{2} \mathrm{Cl}_{2}, \mathrm{DCM}\right)$, methanol $(\mathrm{MeOH}$, HPLC grade), sodium borohydride $\left(\mathrm{NaBH}_{4}, 98 \%\right)$, tetrahydrofuran (high purity, THF) were purchased from Fisher Scientific. 2,4-Dimethylbenzenethiol ( $\mathrm{HSPhMe}_{2}, \mathrm{C}_{8} \mathrm{H}_{9} \mathrm{SH}, 95 \%$ ) and tetraphenylphosphonium bromide $\left(\mathrm{Ph}_{4} \mathrm{PBr}\right)$ were purchased from Alfa Aesar. Dimethylformamide (DMF, HPLC grade), dimethylsulfoxide (DMSO, HPLC grade), and activated carbon (CX0657-1) were purchased from EMD. Milli-Q (Millipore, Bedford, MA) deionized water (resistivity $18.2 \mathrm{M} \Omega \mathrm{cm}$ ) was used in all experiments.

\section{Synthesis and purification of the alkanethiolate-protected $\mathrm{Ag}_{25}$ clusters}

The $\mathrm{Ag}_{25} \mathrm{~L}_{18}{ }^{-}$(where $\mathrm{L}$ is $\mathrm{SPhMe}_{2}$ ) clusters were synthesized using a literature procedure, ${ }^{39}$ with slight modifications. In a typical synthesis, $2.0 \mathrm{~mL}$ of $\mathrm{MeOH}$ was used to dissolve $0.22 \mathrm{mmol}$ of $\mathrm{AgNO}_{3}$ in $50 \mathrm{~mL}$ flask with $5 \mathrm{~min}$ of sonication. Addition of $0.66 \mathrm{mmol}$ of 2,4-dimethylbenzenethiol to this solution gave a thick yellow mixture that became dispersed with the addition of $18 \mathrm{~mL}$ of DCM. This solution was kept in an icebath with constant stirring at $600 \mathrm{rpm}$ for $30 \mathrm{~min}$ before adding a freshly prepared $0.50 \mathrm{~mL}$ methanolic solution containing $0.014 \mathrm{mmol}$ of $\mathrm{PPh}_{4} \mathrm{Br}$. Afterwards, $0.50 \mathrm{~mL}$ of an ice-cold aqueous solution containing $0.40 \mathrm{mmol}$ of $\mathrm{NaBH}_{4}$ was added dropwise and the reaction mixture was continuously stirred in an ice-bath for $6 \mathrm{~h}$. Within this period, the colour of the solution changed from deep yellow to light yellow and finally to a dark red, which indicates the reduction of the silver(I)-thiolate mixture.

The crude solution was aged at $\sim 4{ }^{\circ} \mathrm{C}$ for $18 \mathrm{~h}$ followed by centrifugation (8500 rpm for $30 \mathrm{~min}$ ) to remove a solid that presumably constitutes the excess thiol ligands. The obtained supernatant was then concentrated under rotary evaporator to about $5 \mathrm{~mL}$ before adding $20 \mathrm{~mL}$ of methanol to precipitate the Ag clusters. The precipitate was collected by centrifugation and extracted into $20 \mathrm{~mL}$ of DCM. The DCM solution of the clusters was again centrifuged ( $8500 \mathrm{rpm}$ for $60 \mathrm{~min}$ ) to remove an insoluble yellow solid. Then, the deep red colored supernatant was dried under vacuum, and the obtained purified and dried $\left[\mathrm{Ph}_{4} \mathrm{P}\right]\left[\mathrm{Ag}_{25} \mathrm{~L}_{18}\right]$ clusters were stored in a glass vial under ambient conditions for further studies.

\section{Preparation of carbon-supported $\mathrm{Ag}_{25} \mathrm{~L}_{18}{ }^{-}$clusters}

Immobilization of $\mathrm{Ag}_{25} \mathrm{~L}_{18}{ }^{-}$clusters onto carbon supports was done via the wetness impregnation method, to give a final metal loading of $c a .4 \mathrm{wt} \%$. Typically, $c a .15 .5 \mathrm{mg}$ of $\mathrm{Ag}_{25}$ clusters was dissolved in $5.0 \mathrm{~mL}$ of DCM followed by adding $200 \mathrm{mg}$ of activated carbon and stirring for $24 \mathrm{~h}$. Afterwards, the carbon- 
supported $\mathrm{Ag}_{25} \mathrm{~L}_{18}{ }^{-}$clusters $\left(\mathrm{Ag}_{25} /\right.$ carbon $)$ were first dried at $110^{\circ} \mathrm{C}$ for $2 \mathrm{~h}$ in an oven, and then thermally treated at $250^{\circ} \mathrm{C}$, $350^{\circ} \mathrm{C}$, or $450^{\circ} \mathrm{C}$, for $2 \mathrm{~h}$, at a ramping rate of $10^{\circ} \mathrm{C} \mathrm{min}{ }^{-1}$ under air flow using a Lindberg/Blue $\mathrm{M}$ furnace. The as-prepared and thermally-treated $\mathrm{Ag}_{25} /$ carbon samples were analyzed with TEM, XPS, and XAS (see below).

\section{Characterization techniques}

UV-vis absorption spectroscopy spectra of the $\mathrm{Ag}_{25} \mathrm{~L}_{18}{ }^{-}$clusters in solution were obtained using a Varian Cary 50 UV-visible spectrophotometer with an optical path length of $1 \mathrm{~cm}$. A very small amount of the dried $\mathrm{Ag}_{25} \mathrm{~L}_{18}{ }^{-}$clusters was dissolved in $2.0 \mathrm{~mL}$ of suitable solvent (e.g. DCM) to prepare a sample solution for UV-vis measurements. Thermal gravimetric analyses were performed using a TA Instruments TGA Q5000IR, upon which samples were heated from 25 to $800{ }^{\circ} \mathrm{C}$ under an air flow, with a heating rate of $5{ }^{\circ} \mathrm{C} \min ^{-1}$.

Transmission electron microscopy (TEM) images were collected using a Hitachi HT7700 and HF 3300 TEM operated at $100 \mathrm{kV}$ and $300 \mathrm{kV}$, respectively. TEM samples were prepared by drop casting the $\mathrm{Ag}_{25} \mathrm{~L}_{18}{ }^{-}$cluster solution onto a carbon coated 300 mesh copper TEM grid (Electron Microscopy Sciences, Hatfield, PA) and dried at ambient condition prior to TEM analysis. In the cases of thermally activated $\mathrm{Ag}_{25}$ clusters on carbon, each sample was dispersed in $\mathrm{EtOH}$, and the dispersion was dropped onto a carbon coated copper grid, followed by drying the sample grid at ambient conditions for $2 \mathrm{~h}$ prior to TEM analysis. Average particle sizes were typically determined by manually measuring 100 particles from images obtained for each sample using the ImageJ software program. ${ }^{41}$

X-ray photoelectron spectroscopy (XPS) measurements were collected using a Kratos (Manchester, UK) AXIS Supra system at the Saskatchewan Structural Sciences Centre (SSSC). This system is equipped with a $500 \mathrm{~mm}$ Rowland circle monochromated Al $\mathrm{K} \alpha(1486.6 \mathrm{eV})$ source and combined hemispherical analyzer (HSA) and spherical mirror analyzer (SMA). An accelerating voltage of $15 \mathrm{keV}$, an emission current of $15 \mathrm{~mA}$, and a hybrid spot size of $300 \times 700$ microns were used. All survey scan spectra were collected in the -5 to $1200 \mathrm{eV}$ binding energy range in $1 \mathrm{eV}$ steps with a pass energy of $160 \mathrm{eV}$. High resolution scans of three regions were also conducted using $0.05 \mathrm{eV}$ steps with a pass energy of $20 \mathrm{eV}$. All binding energies were calibrated to the $\mathrm{C} 1 \mathrm{~s}$ of the adventitious carbon at $284.8 \mathrm{eV}$ and spectra were fitted without constraining the full width at half maximum (FWHM) using CasaXPS software. ${ }^{42}$

The Ag K-edge XAS measurements were conducted at the Hard X-ray MicroAnalysis (HXMA) beamline 061D-1 (5-30 keV; resolution $1 \times 10^{-4} \Delta E / E$ ) at the Canadian Light Source (CLS). Energy selection of the Ag K-edge was done using a $\mathrm{Si}(220)$ double-crystal Si monochromator, with a Pt-coated water-cooled collimating KB mirror. Ionization chambers were filled with nitrogen gas. Samples were mixed with boron nitride and measured in fluorescence mode at room temperature using a 32-element detector. The energy of the X-rays was calibrated by using Ag foil. The data processing was performed using the IFEFFIT software package. ${ }^{43}$ The X-ray absorption near-edge structure (XANES) spectra were obtained by subtracting the atomic absorption background and normalizing the spectra to the edge height. The $k^{3}$-weighted spectra were subjected to a Fourier transform (FT) in $R$ space for the $k$ range of $2.8-12 \AA^{-1}$. Ag fcc bulk lattice parameters were used to fit the Ag-foil spectrum, keeping the first shell coordination number fixed $(\mathrm{CN}=$ 12) at first, in order to determine the amplitude reduction factor $\left(\mathrm{S}_{0}{ }^{2}\right)$. From this fitting, the amplitude reduction factor determined for the Ag-foil was 0.80 and was used for subsequent sample fits.

\section{Catalytic measurements for styrene oxidation reactions}

The catalytic performances of the as-prepared and activated $\mathrm{Ag}_{25} /$ carbon samples were evaluated for styrene epoxidation reactions. For each catalyst sample, the catalytic test was conducted inside a $100 \mathrm{~mL}$ round bottom flask fitted with a reflux condenser. A typical reaction set-up includes addition of styrene $(920 \mu \mathrm{L}, 8.0$ $\mathrm{mmol}), \mathrm{TBHP}(3.3 \mathrm{~mL}, 24 \mathrm{mmol}), \mathrm{MeCN}(5.0 \mathrm{~mL})$, and catalyst $(20$ $\mathrm{mg})$ into a flask under reflux and stirring $(600 \mathrm{rpm})$ at a reaction temperature of $82{ }^{\circ} \mathrm{C}$ for $24 \mathrm{~h} .{ }^{13}$ Products were then analyzed using a gas chromatograph (7890A, Agilent Technologies) equipped with a HP-5 column and a flame ionization detector.

\section{Results and discussion}

The formation of a deep-red solution upon addition of sodium borohydride to the $\mathrm{Ag}(\mathrm{I})$-thiolate complex indicates the reduction of $\mathrm{Ag}(\mathrm{I})$ ions and formation of thiolate protected silver clusters. Fig. 1 presents characterization results obtained for purified, unsupported thiolate-protected metal clusters consisting of precisely 25 silver atoms; $\mathrm{Ag}_{25} \mathrm{~L}_{18}{ }^{-}$, where $\mathrm{L}$ is $-\mathrm{SPhMe}_{2}$. Fig. 1(a) shows the UV-vis spectrum of purified $\mathrm{Ag}_{25} \mathrm{~L}_{18}{ }^{-}$clusters in DCM with characteristic peaks at $334 \mathrm{~nm}$, $392 \mathrm{~nm}, 490 \mathrm{~nm}$ and $678 \mathrm{~nm}$ for nearly monodisperse $\mathrm{Ag}_{25} \mathrm{~L}_{18}$
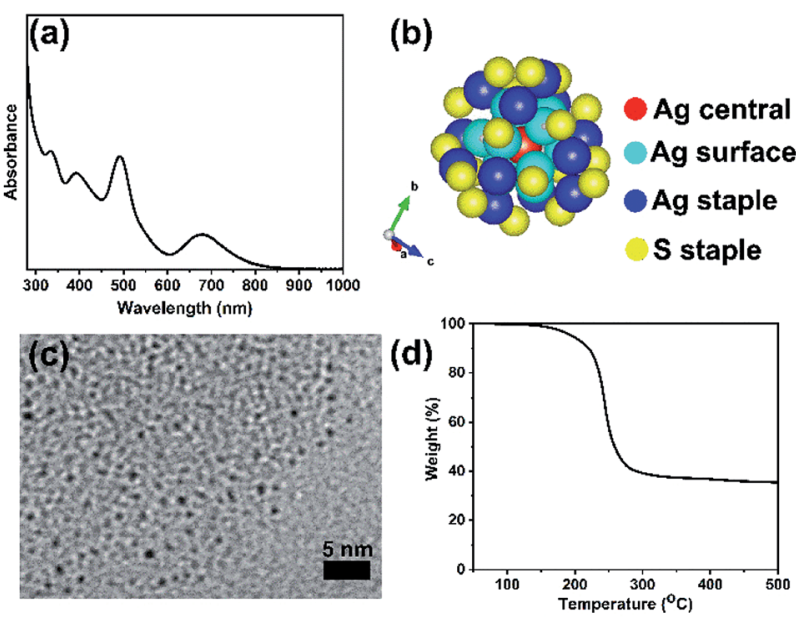

Fig. 1 Characteristic features of $\mathrm{Ag}_{25} \mathrm{~L}_{18}{ }^{-}$clusters (a) UV-vis spectra in DCM, (b) atomic arrangement as visualized using VESTA software, ${ }^{44}$ colour scheme is red for the Ag central atom, light blue for Ag surface atoms, dark blue for Ag staple atoms and yellow for sulfur staple atoms. (c) TEM image, and (d) TGA plot. 
clusters. ${ }^{39}$ Similar to the case for $\mathrm{Au}_{25}$ clusters, the broad peak at around $678 \mathrm{~nm}$ is due to the HOMO-LUMO transition due to the $\mathrm{Ag}_{13}$ icosahedral core in the $\mathrm{Ag}_{25}$ structure. Fig. 1(b) shows the previously determined crystal structure of $\mathrm{Ag}_{25} \mathrm{~L}_{18}{ }^{-},{ }^{39}$ as visualized using the VESTA software package, ${ }^{44}$ to reflect the atomic arrangement and ligand counts. There is one silver atom (red) at the center and twelve silver atoms (dark blue) on the surface of the icosahedral core. The remaining twelve silver atoms (blue) and eighteen sulfur atoms (yellow), from thiolate ligands, constitute atoms in the staple positions. Fig. 1(c) shows a TEM image which shows individual $\mathrm{Ag}_{25} \mathrm{~L}_{18}{ }^{-}$clusters have an average size of $1.0 \pm 0.2 \mathrm{~nm}$. This measurement slightly lesser than a value of $1.5 \pm 0.3 \mathrm{~nm}$ previously reported for $\mathrm{Ag}_{25}(\mathrm{SR})_{18},{ }^{45}$ but closer in line to the expected size of the Ag core. The slight difference in measured average particle size can be due to better size separation, due to extra purification step, in our synthesis procedure, as well as moderate voltage imaging at $100 \mathrm{kV}$ on new sample areas to minimize damage to the clusters by the electron beam. The TGA result in Fig. 1(d) shows no weight loss below $150{ }^{\circ} \mathrm{C}$ and a major weight loss centering around $250{ }^{\circ} \mathrm{C}$, which is presumed to be due to removal of the protecting thiolate ligands from the $\mathrm{Ag}_{25} \mathrm{~L}_{18}{ }^{-}$clusters upon thermal treatment. The final weight percent of material leftover is approximately $40 \%$, which is slightly lower than the theoretically estimated ca. $47 \% \mathrm{Ag}$ composition of the clusters and counter ions, i.e. $\mathrm{Ph}_{4} \mathrm{P}\left[\mathrm{Ag}_{25}(\mathrm{SR})_{18}\right]$.

Table S1 (ESI $\dagger$ ) summarizes the preservation of UV-vis spectroscopy fingerprints of $\mathrm{Ag}_{25} \mathrm{~L}_{18}{ }^{-}$clusters in four different aprotic polar solvents (THF, DMF, DCM, and DMSO), under different storage conditions. Equal concentrations $\left(0.10 \mathrm{mg} \mathrm{mL}^{-1}\right)$ of $\mathrm{Ag}$ clusters were prepared with different solvents and time-dependent UV-vis studies were conducted for clusters stored at room (22-24 $\left.{ }^{\circ} \mathrm{C}\right)$ and cold $\left(\sim 4{ }^{\circ} \mathrm{C}\right)$ temperatures. The fingerprints of $\mathrm{Ag}_{25} \mathrm{~L}_{18}{ }^{-}$ clusters in the UV-vis spectroscopy measurements turn out to be good features for evaluating the stability of clusters in these solvents. The voids in the crystal structure of $\mathrm{Ag}_{25} \mathrm{~L}_{18}{ }^{-}$allow coordination with suitable solvents, and thus can be correlated with the solution-based stability of the $\mathrm{Ag}_{25} \mathrm{~L}_{18}{ }^{-}$clusters. ${ }^{5,39}$ The values of dielectric constant of the selected solvents correlates with the number of days it takes for the precipitation of the $\mathrm{Ag}_{25} \mathrm{~L}_{18}{ }^{-}$clusters, presumably due to loss of coordination of solvent molecules with the voids in the crystal structure of $\mathrm{Ag}_{25} \mathrm{~L}_{18}{ }^{-}$clusters. Both the nature of coordinating solvent and storage temperature affect the solution-based stability of $\mathrm{Ag}_{25} \mathrm{~L}_{18}{ }^{-}$clusters. Importantly, it takes a minimum of $48 \mathrm{~h}$ to observe precipitation of $\mathrm{Ag}_{25} \mathrm{~L}_{18}{ }^{-}$clusters in any of these solvents at room temperature and thus any choice among these solvents is suitable for immobilization of $\mathrm{Ag}_{25} \mathrm{~L}_{18}$ clusters onto carbon supports via wetness impregnation, a procedure that was completed under $24 \mathrm{~h}$, in making heterogeneous catalysts. DCM solvent was chosen for immobilization procedure as it dries quickly due to its lower boiling point.

The activation of heterogeneous catalysts derived from colloidal precursors often entails partial or complete removal of any protecting ligands to enable access of active sites by reactants $^{\mathbf{2 1 , 4 6 - 4 8}}$ While the activation can be achieved by several approaches, thermal calcination approaches to activation are quite simple and thus employed in this present study. TEM,
XPS, and XAS analyses of the $\mathrm{Ag}_{25}$ /carbon samples gave insight into the extent of ligand removal and particle growth at different activation temperatures. Fig. 2 shows TEM images of thermallyactivated $\mathrm{Ag}_{25} /$ carbon catalysts. It is noteworthy that imaging clusters on carbon supports was somewhat difficult due to the small size and poor contrast between the support and clusters. Nevertheless, no appreciable increase in cluster size was noted upon loading the Ag clusters onto carbon supports. This suggests that majority of Ag clusters are effectively adsorbed without structural compromise. Improved contrast was seen between $\mathrm{Ag}$ and the carbon support for $\mathrm{Ag}_{25} /$ carbon samples calcined at $250{ }^{\circ} \mathrm{C}$ and beyond. Average particle sizes were $1.2 \pm$ $0.3 \mathrm{~nm}, 2.6 \pm 0.4 \mathrm{~nm}$, and $2.8 \pm 0.6 \mathrm{~nm}$ for activated samples at $250{ }^{\circ} \mathrm{C}, 350{ }^{\circ} \mathrm{C}$, and $450{ }^{\circ} \mathrm{C}$, respectively. This shows that very minor growth in the average cluster size is seen for samples calcined at $250{ }^{\circ} \mathrm{C}$, while the cluster size grows progressively with higher activation temperatures. Thus, particle growth revealed by TEM images may be a consequence of the removal of protecting thiolate ligands upon thermal activation of asprepared $\mathrm{Ag}_{25} /$ carbon catalysts.

Fig. 3 shows the XPS spectra of the constituent elements of the as-prepared $\mathrm{Ag}_{25} /$ carbon sample; XPS survey maps show the presence of $\mathrm{C}, \mathrm{Ag}, \mathrm{S}$, and $\mathrm{O}$ as the constituent elements. The $\mathrm{C} 1 \mathrm{~s}$ spectrum was fitted with multiple Gaussian components having peaks with binding energies at $284.8 \mathrm{eV}, 284.9 \mathrm{eV}, 285.9 \mathrm{eV}$, and $289.9 \mathrm{eV}$ and these can be attributed to $\mathrm{C}-\mathrm{C} \mathrm{sp}^{2}, \mathrm{C}-\mathrm{C} \mathrm{sp}{ }^{3}, \mathrm{C}-\mathrm{O}$, and $\mathrm{C}=\mathrm{O}$ species respectively; the latter species are commonly found on activated carbon surfaces. ${ }^{49}$ Fig. 3(b) shows the $\mathrm{Ag} 3 \mathrm{~d}_{5 /}$ ${ }_{2}$ and $\mathrm{Ag} 3 \mathrm{~d}_{3 / 2}$ peaks at $368.1 \mathrm{eV}$ and $374.1 \mathrm{eV}$, respectively, which are consistent with silver atoms in the zerovalent state (Ag $\left.3 \mathrm{~d}_{5 / 2}=\sim 368.0 \mathrm{eV}\right){ }^{50,51}$ Deconvolution of the high resolution spectrum of S 2p spectrum, shown in Fig. 3(c), shows two peaks with spin-orbit splitting of $\sim 1.2 \mathrm{eV}$ indicating the presence of Ag-thiolate species $\left(162.2 \mathrm{eV}\right.$ for $\mathrm{S} 2 \mathrm{p}_{3 / 2}$ and $163.5 \mathrm{eV}$ for $\mathrm{S} 2 \mathrm{p}_{1 /}$ 2). ${ }^{52}$ The $\mathrm{O} 1 \mathrm{~s}$ spectrum shows an asymmetric profile that suggests the presence of more than one kind of oxygen species (Fig. 3(d)) on the carbon surface. The deconvolution of the spectrum gives two peaks centering at $\sim 531.2$ and $533.1 \mathrm{eV}$ that can be ascribed to $\mathrm{C}-\mathrm{O}$ and $\mathrm{C}=\mathrm{O}$ species from the activated carbon surface, respectively, and thus the absence of metal oxide species. ${ }^{53}$ Altogether, XPS results indicate that thiolate ligands remain attached to the surface of silver cluster surface and no oxidation of silver atoms occurs in the $\mathrm{Ag}_{25} /$ carbon sample prepared via wetness impregnation.

Fig. 4 shows the XPS spectra and fits of the $\mathrm{Ag} 3 \mathrm{~d}$ peaks for the calcined $\mathrm{Ag}_{25} /$ carbon catalyst samples. In the calcined samples, the $\mathrm{Ag} 3 \mathrm{~d}_{5 / 2}$ and $\mathrm{Ag} 3 \mathrm{~d}_{3 / 2}$ peaks are at $368.03 \mathrm{eV}$ and

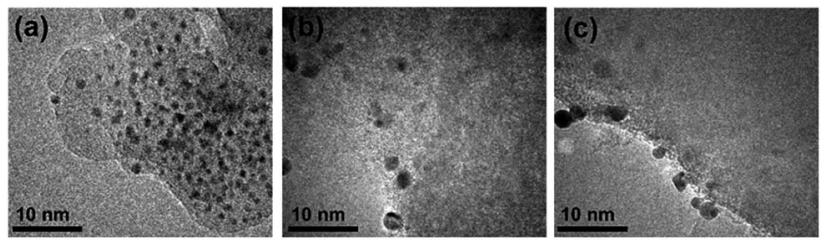

Fig. 2 TEM images of thermally activated $\mathrm{Ag}_{25}$ /carbon catalyst samples at (a) $250{ }^{\circ} \mathrm{C}$ (b) $350{ }^{\circ} \mathrm{C}$, and (c) $450{ }^{\circ} \mathrm{C}$. 

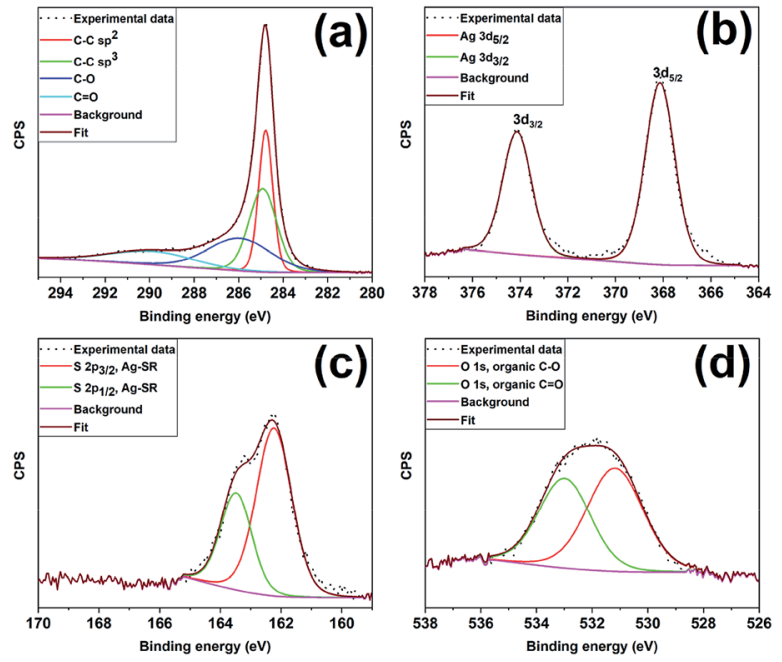

Fig. 3 XPS spectra for the as-prepared $\mathrm{Ag}_{25}$ /carbon catalyst; (a) $\mathrm{C} 1 \mathrm{~s}$ (b) Ag 3d, (c) S 2p and (d) O 1s peaks.

$374.03 \mathrm{eV}$ respectively, which show that silver atoms maintain the zerovalent state after calcination. In contrast, analysis of the S 2p spectra of activated samples shows the absence of peaks earlier ascribed to Ag-thiolate species (Fig. S1, ESI $\dagger$ ). Instead, S $2 \mathrm{p}$ peaks appears at higher binding energies and these peaks can be attributed to the organic disulfide and other oxidized sulfur species like sulfonates, ${ }^{54,55}$ which are byproducts of oxidative dethiolation. Also, there is no indication of formation of silver oxide or sulfide from both $\mathrm{Ag} 3 \mathrm{~d}$ and $\mathrm{O}$ 1s spectra obtained for activated sample (Fig. 4 and S1, ESI $\dagger$ ). Also, from the quantification of survey spectra, the amount of sulfur species decreases with increase in activation temperatures. The sulfur species content was quantified to be $1.40 \%$ in the as-prepared sample, $0.55 \%, 0.14 \%$ and $\sim 0.01 \%$ for activated samples at $250{ }^{\circ} \mathrm{C}, 350{ }^{\circ} \mathrm{C}$, and $450{ }^{\circ} \mathrm{C}$ respectively. These XPS results suggest that thiolate ligands leave the surface of silver clusters upon thermal activation, which is consistent with the TGA results (Fig. 1(d)). Zhang et al. recently reported a similar observation showing migration of protecting ligands from the gold metal surface onto an oxide support upon deposition and oxidative pretreatment. ${ }^{56}$ All XPS results suggest Ag clusters remain in the zerovalent state after calcination, and that no significant Ag oxidation is occurring upon calcination.

XAS experiments were carried out to further examine the structural integrity of $\mathrm{Ag}_{25}$ clusters on carbon supports. While XANES spectroscopy gives information about the oxidation state and local environment, EXAFS spectroscopy affords information about the average coordination number $(\mathrm{CN})$ around metal atoms and bond distances. ${ }^{57}$ Fig. 5 shows the Ag K-edge spectra obtained for as-prepared and activated $\mathrm{Ag}_{25} /$ carbon catalysts, alongside that of $\mathrm{Ag}$ foil as a reference. The spectra show a strong K-edge feature for Ag at $25514 \mathrm{eV}$ which is attributed to dipole-allowed $1 \mathrm{~s}$ to 5 p transition. ${ }^{58}$ Fig. 5(a) shows the XANES spectra of the sample; the peak at ca. $25550 \mathrm{eV}$ is absent in the as-prepared clusters and grows in intensity with increased activation temperature. A number of groups, including our own,

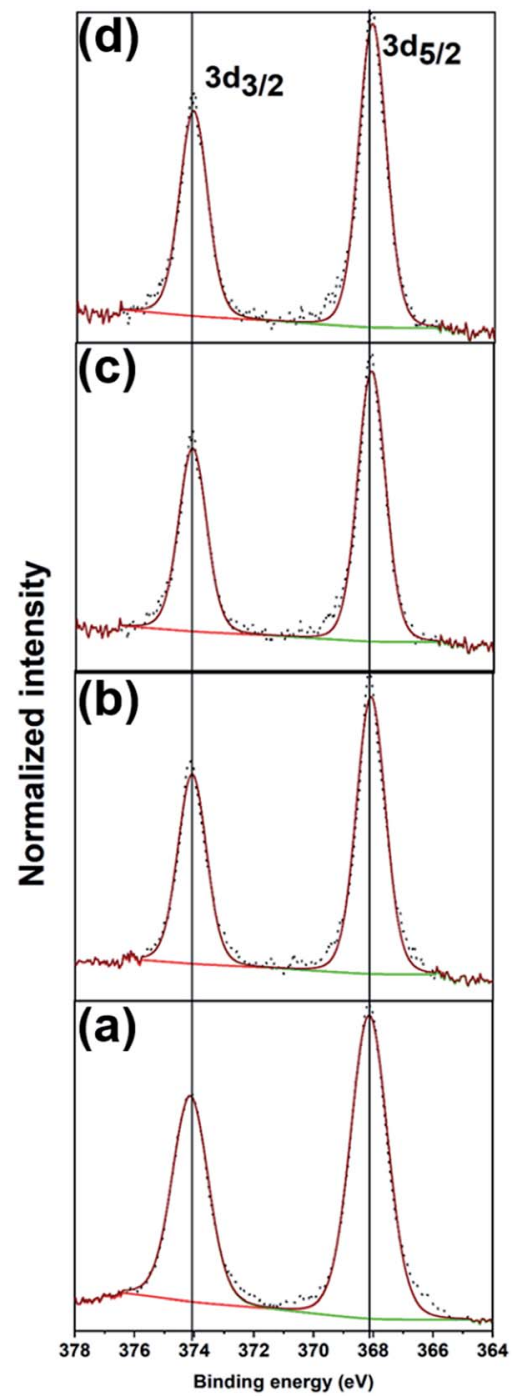

Fig. 4 XPS spectra of Ag 3d peaks for (a) as-prepared, and the calcined $\mathrm{Ag}_{25} /$ carbon catalyst samples at (b) $250^{\circ} \mathrm{C}$, (c) $350^{\circ} \mathrm{C}$, and (d) $450^{\circ} \mathrm{C}$.

have observed that this multiple scattering feature is a good fingerprint for $\mathrm{Au}$ cluster growth in analogous $\mathrm{Au}$ cluster samples (i.e. small clusters do not have such multiple scattering peaks given their small size). ${ }^{12,17,18}$ This agrees well with previous TEM results from these samples. The as-prepared sample shows distinct near edge features to suggest that the neighboring atoms are different for the as-prepared sample as compared to activated samples. Comparing the near edge features with those of reference $\mathrm{Ag}$ foil, it shows that $\mathrm{Ag}-\mathrm{Ag}$ interactions become more predominant at calcination temperatures above $250{ }^{\circ} \mathrm{C}$ which affirms that cluster sintering becomes problematic beyond $250{ }^{\circ} \mathrm{C}$. This agrees with the results from both TGA and XPS, confirming the removal of protecting thiolate ligands upon thermal activation of asprepared $\mathrm{Ag}_{25} /$ carbon catalyst. It is noteworthy that the spectra features of all the samples show no detectable $\mathrm{Ag}_{2} \mathrm{O}$ or $\mathrm{Ag}_{2} \mathrm{~S}$ in these samples, in consistent with the XPS results (Fig. 3, 4 and $\mathrm{S} 1, \mathrm{ESI} \dagger)$. 

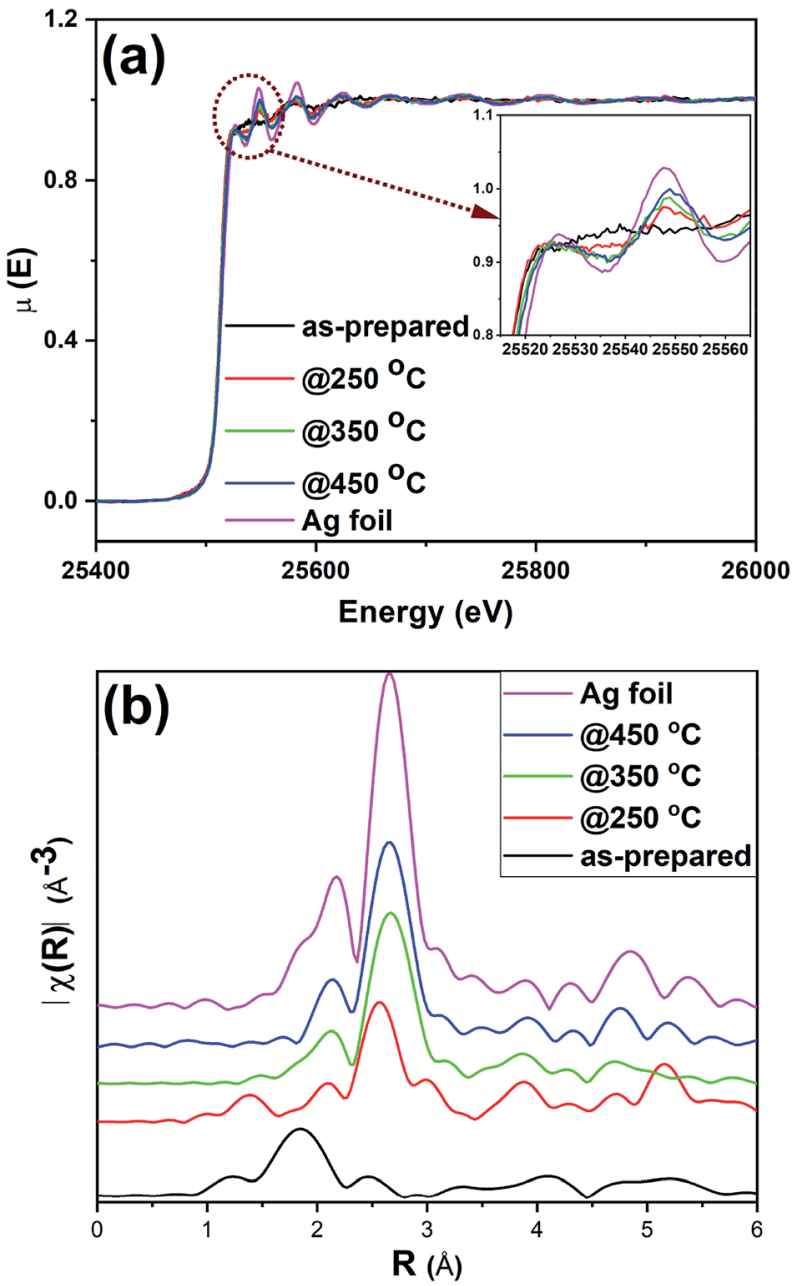

Fig. 5 Ag K-edge (a) XANES and (b) FT-EXAFS spectra in $R$-space for as-prepared and activated $\mathrm{Ag}_{25}$ /carbon catalysts and $\mathrm{Ag}$ foil reference.

Fig. 5(b) shows the Ag K edge EXAFS spectra of the $\mathrm{Ag}_{25} /$ carbon samples in $R$-space. EXAFS measurements are sensitive to the bonding environment of the absorbing atom. All samples, as well as the reference $\mathrm{Ag}$ foil, show major peaks at around 2.72 $\AA$ (note the plotted data has no phase shift correction) that are characteristic features of first shell $\mathrm{Ag}-\mathrm{Ag}$ contributions (Fig. 5(b)), while only the as-prepared sample has a Ag-S feature in the $1.85 \AA$ region. The crystallographic information of $\mathrm{Ag}_{25} \mathrm{~L}_{18}{ }^{-}$provided in the literature was used to make the theoretical model for fitting the experimental data obtained for asprepared sample using a two-shell fitting approach. ${ }^{39} \mathrm{~A}$ similar approach was reported for EXAFS fittings of $\mathrm{Ag}_{44}(\mathrm{SR})_{30}{ }^{4-}$ clusters. ${ }^{20}$ The fitting parameters such as $\mathrm{CN}$, nearest neighbour distance $(R)$, Debye-Waller factors $\left(\sigma^{2}\right)$, and energy shift $\left(E_{\mathrm{o}}\right)$ are presented in Table S2 (ESI $\dagger)$, while the k-space and R-space plots are shown in Fig. S2 (ESI $\dagger$ ). The bond distance of 2.401(6) A was obtained for the Ag-S contribution from the fit and this value agrees very well with values of $2.382-2.445 \AA$ earlier reported for $\mathrm{Ag}-\mathrm{S}$ bond in the crystal structure, ${ }^{39}$ and a value of 2.81(2) $\AA$ was obtained for $\mathrm{Ag}-\mathrm{Ag}$ bond distance in the as-prepared sample. $\mathrm{CN}$ values of $1.08(5)$ and $0.5(1)$ were obtained for $\mathrm{Ag}-\mathrm{S}$ and $\mathrm{Ag}-\mathrm{Ag}$ bonds, respectively. We note that the $\mathrm{CN}$ value for first shell $\mathrm{Ag}-\mathrm{Ag}$ interactions is low but this can be due to both the presence of multiple first shell $\mathrm{Ag}-\mathrm{Ag}$ contributions and perhaps low levels of Ag thiolate impurities. Attempts to use multiple $\mathrm{Ag}-\mathrm{Ag}$ first shells in fitting were unsuccessful as the data quality was not sufficient for such a detailed analysis. ${ }^{18,59}$ Nevertheless, the data suggests successful immobilization of $\mathrm{Ag}_{25} \mathrm{~L}_{18}{ }^{-}$clusters onto carbon supports without compromising their structural integrity. ${ }^{39}$ In summary, XPS and XAS data of as-prepared $\mathrm{Ag}_{25} /$ carbon catalysts suggest that the structural changes in activated $\mathrm{Ag}_{25} /$ carbon samples can be solely due to calcination which causes removal of protecting ligands from $\mathrm{Ag}_{25} \mathrm{~L}_{18}{ }^{-}$clusters.

In addition to the observable changes in the near edge features in XANES spectra (Fig. 5(a)), a single-shell fit approach is employed to analyze the EXAFS data obtained for thermally treated $\mathrm{Ag}_{25} /$ carbon samples to probe the growth in cluster size with increasing activation temperatures. The single-shell fit entails the use of a $\mathrm{Ag}$ fcc model and is adopted due to observed growth in cluster size and presence of zerovalent $\mathrm{Ag}$ as revealed by the other results. Fig. S3 (ESI $\uparrow$ ) shows both $k$-space and $R$ space EXAFS spectra at the Ag K-edge for the thermally activated $\mathrm{Ag}_{25} /$ carbon samples, and the obtained fitting parameters are presented in Table 1 . The first shell $\mathrm{Ag}-\mathrm{Ag}$ coordination number (CN) increases with an increase in activation temperature; this agrees with the increase in the peak intensities of the $R$-space EXAFS spectra (Fig. 5(b)). No significant Ag-S contributions were found for any of the calcined samples. For samples thermally activated at $250{ }^{\circ} \mathrm{C}, 350^{\circ} \mathrm{C}$, and $450^{\circ} \mathrm{C}$, the first shell $\mathrm{Ag}$ $\mathrm{Ag} \mathrm{CN}$ values are 3.8(7), 6.1(3), and 6.3(3), respectively. A CN value of $3.8(7)$ for sample activated at $250{ }^{\circ} \mathrm{C}$ and $6.1(3)$ for sample activated at $350{ }^{\circ} \mathrm{C}$ suggest significant structural changes occur at higher calcination temperatures due to sintering of $\mathrm{Ag}$ clusters. There is no significant change in the Debye-Waller parameter which indicates that the degree of disorder remains unchanged with the increase in activation temperature. However, the $\mathrm{Ag}-\mathrm{Ag}$ bond distance slightly increases with activation temperature which is also consistent with an increase in cluster size. ${ }^{20,58,60}$ Altogether, it can be said that the protecting thiolate ligands are completely removed with little compromise in the size of $\mathrm{Ag}_{25}$ clusters by thermal activation at $250{ }^{\circ} \mathrm{C}$, whereas higher temperature calcination leads to moderate cluster sintering.

Estimation of average particle sizes $\left(d_{\text {mean }}\right)$ directly from EXAFS CNs is reported in the literature. ${ }^{61-63}$ Recently, Wei et al. (2013) reported an equation that quantitatively relates the $\mathrm{CN}$ from EXAFS fittings to average particle size using Ag nanoparticle sizes obtained by analyzing STEM images (for particles ranging from 0.8 to $8.7 \mathrm{~nm}$ in size). ${ }^{63}$ The equation was modified to give eqn (1) below that can directly estimate the average particle size in nanometers $(\mathrm{nm})$. Using the concept of error propagation, ${ }^{64}$ eqn (2) was derived to estimate the error in $d_{\text {mean }}$ in eqn (1). These two equations enable estimation of size distribution using $\mathrm{CN}$ errors from EXAFS fittings.

$$
d_{\text {mean }}(\mathrm{nm})=10^{((0.1319 \times \mathrm{CN})-0.5763)}
$$


Table 1 Single shell EXAFS fitting parameters for activated $\mathrm{Ag}_{25}$ /carbon catalysts

\begin{tabular}{llllr}
\hline Catalyst & $\mathrm{CN}(\mathrm{Ag}-\mathrm{Ag})$ & $R \AA^{-1}(\mathrm{Ag}-\mathrm{Ag})$ & $\sigma^{2} / \AA^{2}(\mathrm{Ag}-\mathrm{Ag})$ & $\begin{array}{l}E_{\mathrm{o}} \text { shift/eV } \\
(\mathrm{Ag}-\mathrm{Ag})\end{array}$ \\
\hline @250 ${ }^{\circ} \mathrm{C}$ & $3.8(7)$ & $2.826(6)$ & $0.0080(2)$ & $-3.7(8)$ \\
@ $350^{\circ} \mathrm{C}$ & $6.1(3)$ & $2.854(5)$ & $0.0090(7)$ & $-1.9(5)$ \\
(a) $450^{\circ} \mathrm{C}$ & $6.3(3)$ & $2.859(6)$ & $0.0081(8)$ & $-0.7(6)$
\end{tabular}

$$
\sigma_{\mathrm{d}}=\left|d\left(0.1319 \times \ln (10) \sigma_{\mathrm{CN}}\right)\right|
$$

Using the two equations above, the average cluster size was estimated to be $0.84 \pm 0.18 \mathrm{~nm}, 1.69 \pm 0.15 \mathrm{~nm}$, and $1.80 \pm$ $0.16 \mathrm{~nm}$ for $\mathrm{Ag}_{25} /$ carbon samples activated at $250{ }^{\circ} \mathrm{C}, 350{ }^{\circ} \mathrm{C}$ and $450{ }^{\circ} \mathrm{C}$ respectively. These values are somewhat consistent with the average cluster sizes measured from TEM images of $1.2 \pm 0.3 \mathrm{~nm}$, $2.6 \pm 0.4 \mathrm{~nm}$, and $2.8 \pm 0.6 \mathrm{~nm}$, respectively (Fig. 2), though TEM measurements slightly over-represent cluster sizes. Determining precise particle sizes and distributions when dealing with clusters in the nanometer size range by TEM can be difficult in that subnanometer clusters may be present that are not easily observed. Thus, as the TEM particle sizes for the three activated samples are larger than the mean diameters calculated from first-shell $\mathrm{CN}$ values, this suggests there may be a population of smaller clusters which are difficult to image by TEM in the samples.

Selective oxidation of olefins to epoxides is a desirable chemical conversion in the fine chemical industry, and the use of heterogeneous Ag-based catalysts has gained attention in recent years. ${ }^{65}$ Specifically, styrene to styrene oxide (SO) conversion is a desirable chemical process in industry as SO is a useful chemical in the production of surface coatings and cosmetics. ${ }^{65,66} \mathrm{SO}$ is also beneficial to the production of styrene glycol, polyurethanes, and cross-linked polyesters. ${ }^{66}$ Both activity and selectivity are important parameters for describing performance of catalysts in a given reaction. Table 2 presents the results obtained for the catalytic evaluation of $\mathrm{Ag}_{25} /$ carbon as catalysts in styrene oxidation reactions. Catalytic activity was measured in terms of both conversion and an average turnover number (TON), which was determined as moles of converted styrene per moles of $\mathrm{Ag}$ in the catalyst. No activity was observed in blank reactions (without catalyst or carbon support) and

Table 2 Catalytic performances of support, as-prepared and activated $\mathrm{Ag}_{25} /$ carbon catalysts $^{a}$

\begin{tabular}{lllllll}
\hline & \multicolumn{2}{l}{ Activity } & & \multicolumn{2}{l}{ Selectivity } \\
\cline { 2 - 3 } Catalyst & Conversion (\%) & TON & & SO (\%) & BA (\%) \\
\hline Carbon support & 15.3 & & 90.9 & 9.1 \\
$\mathrm{Ag}_{25} /$ carbon as-prepared & 51.6 & 1114 & 95.1 & 4.9 \\
$\mathrm{Ag}_{25} /$ carbon@250 ${ }^{\circ} \mathrm{C}$ & 61.4 & 1325 & 94.0 & 6.0 \\
$\mathrm{Ag}_{25} /$ carbon@350 & ${ }^{\circ} \mathrm{C}$ & 49.9 & 1078 & 92.6 & 7.4 \\
$\mathrm{Ag}_{25} /$ carbon@450 & ${ }^{\circ} \mathrm{C}$ & 46.6 & 1006 & 89.4 & 10.6
\end{tabular}

${ }^{a}$ Reaction conditions: styrene $(8.0 \mathrm{mmol})$, TBHP $(24 \mathrm{mmol}), \mathrm{MeCN}$ (5.0 $\mathrm{mL})$, catalyst $(20 \mathrm{mg})$ in a flask under reflux, stirring speed $(600 \mathrm{rpm})$, reaction temperature of $\left(82{ }^{\circ} \mathrm{C}\right)$, reaction time $(24 \mathrm{~h})$. Ratio of substrate to metal is $2157: 1$. TON $=$ moles of product $/$ moles of Ag. about $1 \%$ conversion of styrene was recorded when air was used as oxidant instead of tert-butyl hydroperoxide (TBHP), in the presence of our catalysts. Significant activity was observed with TBHP as an oxidant and thus data obtained for styrene oxidation reaction with TBHP were used to compare the performances of studied catalysts. Interestingly, carbon supports alone showed about $15 \%$ conversion of styrene, on average, under our reaction conditions. The results show that $\mathrm{Ag}_{25} /$ carbon catalysts display size-dependent activities with SO as a major product for all examined catalysts in this study. The range of values obtained for selectivity for styrene oxide is in agreement with those reported for $\mathrm{Au}_{25}$ clusters in literature. ${ }^{\mathbf{1 0 , 1 3}}$ The TON of as-prepared catalysts was found to be 1114 and it increased to 1325 for catalysts activated at $250{ }^{\circ} \mathrm{C}$. This increase in TON value can be ascribed to significant removal of protecting ligands off the catalyst surface which enables better access of the active sites by the substrate. The subsequent drop in TON values for catalysts activated at higher temperatures is due to particle sintering as indicated by the increase in the CN values in the XAS measurements and average particle sizes in the TEM measurements. The small trend obtained for product selectivity may be due to particle size effects, as the clusters increase in size at higher calcination temperatures.

Others have shown that TBHP works as a radical initiator, when present in sub-stoichiometric quantities, which then allows the reaction to proceed with oxygen as the main oxidant. ${ }^{67,68}$ Using the $\mathrm{Ag}_{25} /$ carbon@250 ${ }^{\circ} \mathrm{C}$ catalyst, we performed reactions with substoichiometric amounts of TBHP and for longer reaction times, and the results are presented in Table 3 . The reduction in amount of TBHP from $24 \mathrm{mmol}$ (i.e. $300 \%$ of styrene amount) to $0.40 \mathrm{mmol}$ (i.e. $5 \%$ of styrene amount) leads to a decrease in the styrene conversion from $61.4 \%$ to $5.8 \%$ for a reaction period of $24 \mathrm{~h}$, and no conversion is seen in the complete absence of TBHP initiator. However, by extending the reaction period to $72 \mathrm{~h}$, a conversion of $23.3 \%$ is observed with $0.40 \mathrm{mmol}$ TBHP. This indicates that the reaction proceeds at a much slower rate when catalytic amounts of TBHP are used as radical initiator and molecular oxygen is the major oxygen atom source for the epoxide formation. Similar observations were reported in separate studies for $\mathrm{Au}$ and $\mathrm{Ag}$ nanoparticle catalysts. ${ }^{68,69}$ Thus, a radical mechanism is occurring for styrene epoxidation over the activated $\mathrm{Ag}_{25} /$ carbon catalysts, in which the thermolysis of $t$ - $\mathrm{BuOOH}$ (TBHP) occurs on the surface of silver particles to give $t$-BuOO${ }^{\circ}$ and $\mathrm{H}^{*}$ radicals, as reported for similar systems ${ }^{68,70}$ It is of note that the selectivity towards epoxide formation is tremendously reduced when using sub-stoichiometric amounts of TBHP. The decrease in the selectivity is consistent with results in the literature as TBHP as an oxidant has been identified to be more selective for epoxide formation. ${ }^{69}$ The spent catalyst was 
Table 3 Catalytic performance of activated $\mathrm{Ag}_{25} /$ carbon $a 250{ }^{\circ} \mathrm{C}$ catalyst with sub-stoichiometric amounts of $\mathrm{TBHP}^{a}$

\begin{tabular}{|c|c|c|c|c|c|}
\hline \multicolumn{2}{|l|}{ Entry } & \multicolumn{2}{|l|}{ Activity } & \multicolumn{2}{|c|}{ Selectivity } \\
\hline Cycle & $\begin{array}{l}\text { Reaction } \\
\text { time }\end{array}$ & Conversion (\%) & TON & SO (\%) & $\mathrm{BA}(\%)$ \\
\hline \multirow[t]{2}{*}{ First } & $24 \mathrm{~h}$ & 5.8 & 125 & 60.8 & 39.2 \\
\hline & $72 \mathrm{~h}$ & 23.3 & 502 & 59.6 & 40.4 \\
\hline \multirow[t]{2}{*}{ Second } & $24 \mathrm{~h}$ & 7.2 & 155 & 59.8 & 40.2 \\
\hline & $72 \mathrm{~h}$ & 46.2 & 997 & 61.0 & 39.0 \\
\hline \multirow[t]{2}{*}{ Third } & $24 \mathrm{~h}$ & 7.4 & 160 & 59.6 & 40.4 \\
\hline & $72 \mathrm{~h}$ & 46.7 & 1007 & 61.2 & 38.8 \\
\hline
\end{tabular}

${ }^{a}$ Reaction conditions: styrene $(8.0 \mathrm{mmol})$, TBHP $(0.4 \mathrm{mmol}), \mathrm{MeCN}(5.0$ $\mathrm{mL})$, catalyst $(20 \mathrm{mg})$ in a flask under reflux, stirring speed $(600 \mathrm{rpm})$, reaction temperature of $\left(82{ }^{\circ} \mathrm{C}\right)$. Ratio of substrate to metal is $2157: 1$. TON $=$ moles of product $/$ moles of Ag.

subjected to a recycling process that involves washing the spent catalyst with acetone for three times, followed by oven drying at $110^{\circ} \mathrm{C}$ for $30 \mathrm{~min}$. Thereafter, the recycled catalyst was used for two more cycles of reaction and it was found to have slightly higher activity and similar selectivity. The increase in activity after the first cycle of reaction may be due to the removal of organic sulfur species adsorbed on the catalyst surface by washing steps utilized to recycle the catalyst.

\section{Conclusions}

Atomically precise $\mathrm{Ag}_{25} \mathrm{~L}_{18}{ }^{-}$clusters were synthesized and deposited onto carbon supports for catalysis. Carbon-supported $\mathrm{Ag}_{25}$ clusters were activated at mild temperatures $\left(250{ }^{\circ} \mathrm{C}\right)$ without sintering, while growth in particle sizes was observed at higher calcination temperatures. Upon thermal activation, the protecting thiolate ligands were detached from the surface of $\mathrm{Ag}_{25}$ clusters and the products of dethiolation were adsorbed onto the carbon supports, and these sulfur species were further removed at high temperatures. XPS and XAS data both showed that the resulting activated Ag clusters have metallic character, and $\mathrm{Ag}_{2} \mathrm{~S}$ formation was not observed. Both as-prepared and activated $\mathrm{Ag}_{25}$ /carbon catalysts showed high selectivity towards styrene oxide, with maximum activities and selectivities seen for clusters activated at $250{ }^{\circ} \mathrm{C}$. The catalytic performance of the catalyst was dramatically reduced when sub-stoichiometric, catalytic amounts of TBHP were used. Results showed that the reaction progressed much more slowly and with much lower selectivity using $\mathrm{O}_{2}$ as the major oxygen source for epoxide formation, which suggests that TBHP is a better oxidant for the highly selective formation of epoxides. Future work will focus on using such activated $\mathrm{Ag}_{25}$ /carbon catalysts as starting materials for the design of $\mathrm{Ag}$ based bimetallic clusters with other metals using galvanic replacement methods.

\section{Conflicts of interest}

There are no conflicts to declare.

\section{Acknowledgements}

The authors acknowledge financial assistance from the National Sciences and Engineering Research Council of Canada (NSERC). XAS experiments were performed at Canadian Light Source (CLS), which is supported by the NSERC, the National Research Council Canada, the Canadian Institutes of Health Research, the Province of Saskatchewan, Western Economic Diversification Canada, and the University of Saskatchewan. Charles Soong and Stas Dogel (Hitachi) are acknowledged for assistance with HRTEM analysis. We also thank Larhonda Sobchishin at the WCVM Imaging Center, University of Saskatchewan and Ning Chen at the HXMA Beamline at the CLS for their assistance.

\section{Notes and references}

1 M. Haruta, T. Kobayashi, H. Sano and N. Yamada, Chem. Lett., 1987, 16, 405-408.

2 R. Jin, C. Zeng, M. Zhou and Y. Chen, Chem. Rev., 2016, 116, 10346-10413.

3 J. Zeng, Q. Zhang, J. Chen and Y. Xia, Nano Lett., 2010, 10, 3035.

4 N. Li, X. Lai, P. Zhao, G. Yue, D. Astruc, M. Shuai and S. Su, Coord. Chem. Rev., 2015, 311, 75-84.

5 C. P. Joshi, O. F. Mohammed, M. S. Bootharaju, O. M. Bakr and M. R. Parida, Angew. Chem., Int. Ed., 2015, 55, 922-926.

6 X. Yuan, X. Dou, K. Zheng and J. Xie, Part. Part. Syst. Charact., 2015, 32, 613-629.

7 J. Wang, G. Wang and J. Zhao, Phys. Rev. B: Condens. Matter Mater. Phys., 2002, 66, 1-6.

8 L. Wang, J. Zhang, Y. Zhu, S. Xu, C. Wang, C. Bian, X. Meng and F. S. Xiao, ACS Catal., 2017, 7, 7461-7465.

9 Y. Zhu, H. Qian, M. Zhu and R. Jin, Adv. Mater., 2010, 22, 1915-1920.

10 Y. Liu, H. Tsunoyama, T. Akita and T. Tsukuda, Chem. Commun., 2010, 46, 550-552.

11 G. Li, D. E. Jiang, S. Kumar, Y. Chen and R. Jin, ACS Catal., 2014, 4, 2463-2469.

12 A. Shivhare, D. M. Chevrier, R. W. Purves and R. W. J. Scott, J. Phys. Chem. C, 2013, 117, 20007-20016.

13 V. Sudheeshkumar, A. Shivhare and R. W. J. Scott, Catal. Sci. Technol., 2017, 7, 272-280.

14 T. Chen, R. R. Nasaruddin, M. J. Hülsey, J. Xie, Q. Yao and N. Yan, Nanoscale, 2018, 10, 23113-23121.

15 J. Zhao and R. Jin, Nano Today, 2018, 18, 86-102.

16 D. M. Chevrier, R. Yang, A. Chatt and P. Zhang, Nanotechnol. Rev., 2015, 4, 193-206.

17 A. I. Frenkel, Chem. Soc. Rev., 2012, 41, 8163-8178.

18 M. A. MacDonald, D. M. Chevrier, P. Zhang, H. Qian and R. Jin, J. Phys. Chem. C, 2011, 115, 15282-15287.

19 K. E. Lee, A. Shivhare, Y. Hu and R. W. J. Scott, Catal. Today, 2017, 280, 259-265.

20 M. Urushizaki, H. Kitazawa, S. Takano, R. Takahata, S. Yamazoe and T. Tsukuda, J. Phys. Chem. C, 2015, 119, 27483-27488. 
21 Q. Ge, H. Xu, R. Jin, X. Nie and H. Qian, ACS Nano, 2012, 6, 6014-6022.

22 G. M. Veith, A. R. Lupini, S. Rashkeev, S. J. Pennycook, D. R. Mullins, V. Schwartz, C. A. Bridges and N. J. Dudney, J. Catal., 2009, 262, 92-101.

23 H. Yin, Z. Ma, H. Zhu, M. Chi and S. Dai, Appl. Catal., A, 2010, 386, 147-156.

24 J. Fang, J. Li, B. Zhang, X. Yuan, H. Asakura, T. Tanaka, K. Teramura, J. Xie and N. Yan, Nanoscale, 2015, 7, 63256333.

25 Y. Zhu, H. Qian and R. Jin, Chem.-Eur. J., 2010, 16, 1145511462.

26 M. Dasog, W. Hou and R. W. J. Scott, Chem. Commun., 2011, 47, 8569-8571.

27 S. M. Ansar, F. S. Ameer, W. Hu, S. Zou, C. U. Pittman and D. Zhang, Nano Lett., 2013, 13, 1226-1229.

28 E. W. Elliott, R. D. Glover and J. E. Hutchison, ACS Nano, 2015, 9, 3050-3059.

29 J. Kilmartin, R. Sarip, R. Grau-Crespo, D. Di Tommaso, G. Hogarth, C. Prestipino and G. Sankar, ACS Catal., 2012, 2, 957-963.

30 F. X. Xiao, Z. Zeng, S. H. Hsu, S. F. Hung, H. M. Chen and B. Liu, ACS Appl. Mater. Interfaces, 2015, 7, 28105-28109.

31 Y. Zhu, H. Qian, A. Das and R. Jin, Chin. J. Catal., 2011, 32, 1149-1155.

32 R. Xu, D. Wang, J. Zhang and Y. Li, Chem.-Asian J., 2006, 1, 888-893.

33 L. Zhou, C. F. Gorin and R. J. Madix, J. Am. Chem. Soc., 2010, 132, 434-435.

34 X. Yuan, M. I. Setyawati, A. S. Tan, C. N. Ong, D. T. Leong and J. Xie, NPG Asia Mater., 2013, 5, e39.

35 F. D. David, A. G. Kantor, I. J. Rankine, S. K. Wheeler, J. F. Wheeler, M. Ganguly, J. T. Petty and O. O. Sergev, Anal. Chem., 2015, 87, 5302-5309.

36 K. P. Remya, T. Udayabhaskararao and T. Pradeep, J. Phys. Chem. C, 2012, 116, 26019-26026.

37 A. Desireddy, B. E. Conn, J. Guo, B. Yoon, R. N. Barnett, B. M. Monahan, K. Kirschbaum, W. P. Griffith, R. L. Whetten, U. Landman and T. P. Bigioni, Nature, 2013, 501, 399-402.

38 K. Zheng, X. Yuan and J. Xie, Chem. Commun., 2017, 53, 9697-9700.

39 C. P. Joshi, M. S. Bootharaju, M. J. Alhilaly and O. M. Bakr, J. Am. Chem. Soc., 2015, 137, 11578-11581.

40 J. D. Padmos and P. Zhang, J. Phys. Chem. C, 2012, 116, 23094-23101.

41 C. A. Schneider, W. S. Rasband and K. W. Eliceiri, Nat. Methods, 2012, 9, 671-675.

42 M. W. Gaultois and A. P. Grosvenor, J. Phys. Chem. C, 2010, 114, 19822-19829.

43 B. Ravel and M. Newville, J. Synchrotron Radiat., 2005, 12, 537-541.

44 K. Momma and F. Izumi, J. Appl. Crystallogr., 2008, 41, 653658.

45 X. L. Du, X. L. Wang, Y. H. Li, Y. L. Wang, J. J. Zhao, L. J. Fang, L. R. Zheng, H. Tong and H. G. Yang, Chem. Commun., 2017, 53, 9402-9405.
46 H. Yamamoto, H. Yano, H. Kouchi, Y. Obora, R. Arakawa and H. Kawasaki, Nanoscale, 2012, 4, 4148-4154.

47 J. Fang, B. Zhang, Q. Yao, Y. Yang, J. Xie and N. Yan, Coord. Chem. Rev., 2016, 322, 1-29.

48 R. R. Nasaruddin, T. Chen, N. Yan and J. Xie, Coord. Chem. Rev., 2018, 368, 60-79.

49 J. C. Lascovich and S. Scaglione, Appl. Surf. Sci., 1994, 78, 1723.

50 X. She and M. Flytzani-Stephanopoulos, J. Catal., 2006, 237, 79-93.

51 G. Corro, E. Vidal, S. Cebada, U. Pal, F. Bañuelos, D. Vargas and E. Guilleminot, Appl. Catal., B, 2017, 216, 1-10.

52 A. Majid, F. Bensebaa, P. L'Ecuyer, G. Pleizier and Y. Deslandes, Rev. Adv. Mater. Sci., 2003, 4, 25-31.

53 D. G. Castner, K. Hinds and D. W. Grainger, Langmuir, 2002, 12, 5083-5086.

54 D. Schilter, Nat. Rev. Chem., 2017, 1, 0013.

55 J. P. R. Chauvin and D. A. Pratt, Angew. Chem., Int. Ed., 2017, 56, 6255-6259.

56 B. Zhang, A. Sels, G. Salassa, S. Pollitt, V. Truttmann, C. Rameshan, J. Llorca, W. Olszewski, G. Rupprechter, T. Bürgi and N. Barrabés, ChemCatChem, 2018, 10, 53725376.

57 J. W. Niemantsverdriet, Spectroscopy in catalysis: An introduction, Wiley-VCH Verlag GmbH \& Co. KGaA, 3rd edn, 2007.

58 M. K. Gangishetty, R. W. J. Scott and T. L. Kelly, Dalton Trans., 2016, 45, 9827-9834.

59 J. D. Padmos, D. J. Morris and P. Zhang, Can. J. Chem., 2018, 96, 749-754.

60 J. Timoshenko, S. Roese, H. Hövel and A. I. Frenkel, Radiat. Phys. Chem., 2018, 1-4.

61 F. B. M. Duivenvoorden, B. J. Kip, D. C. Koningsberger and R. Prins, J. Phys. Colloq., 2007, 47, 227-230.

62 B. S. Clausen, L. Grabaek, H. Topsoe, L. B. Hansen, P. Stoltze, J. K. Norskov and O. H. Nielsen, J. Catal., 1993, 141, 368-379.

63 H. Wei, C. Gomez, J. Liu, N. Guo, T. Wu, R. Lobo-Lapidus, C. L. Marshall, J. T. Miller and R. J. Meyer, J. Catal., 2013, 298, 18-26.

64 Summary of Rules for Error Propagation, https:// sites.fas.harvard.edu/ scphys/nsta/error_propagation.pdf.

65 X. Y. Dong, Z. W. Gao, K. F. Yang, W. Q. Zhang and L. W. Xu, Catal. Sci. Technol., 2015, 5, 2554-2574.

66 R. Mckenna, S. Pugh, B. Thompson and D. R. Nielsen, Biotechnol. J., 2013, 8, 1465-1475.

67 E. Tebandeke, C. Coman, K. Guillois, G. Canning, E. Ataman, J. Knudsen, L. R. Wallenberg, H. Ssekaalo, J. Schnadt and O. F. Wendt, Green Chem., 2014, 16, 1586-1593.

68 Z. Chen and R. L. Luck, Green Chem., 2016, 18, 3354-3359.

69 S. Bawaked, N. F. Dummer, N. Dimitratos, D. Bethell, Q. He, C. J. Kiely and G. J. Hutchings, Green Chem., 2009, 11, 10371044.

70 M. Vandichel, K. Leus, P. Van Der Voort, M. Waroquier and V. Van Speybroeck, J. Catal., 2012, 294, 1-18. 